\title{
Theoretical Analysis of Household Heat Metering of Central Heating and Its Application
}

\author{
Wang Limei \& Pi Fengmei \\ Engineering College in Langfang teachers college, china
}

\begin{abstract}
Central heating medium heat metering is principle of thermodynamics, drawing on some European the experiences of developed countries, and in China's cities such as Beijing, tianjin, the pilot work has achieved great results. The heat enterprises establishing market economy ideas primary, grades have improved significantly in quality and services for heating. Heat supply system in heat supplying enterprises toward the market, users become God, this makes heating enterprises and consciously shift attitudes and take the initiative to improve the quality of service.
\end{abstract}

KEYWORD: Central heating, Metering, Thermodynamics, application

\section{BASIC PRINCIPLES OF HOUSEHOLD HEAT METERING}

Thermal Physics is defined as: the irregular motion of molecules, heat energy is defined as the kinetic energy. A measurement of temperature is a measure of energy, is the measure of average kinetic energy of molecular motion. Under normal circumstances, we can use the Interior radiator cooling needed to provide home heating energy. This process of conduction, convection and radiation factors at work. During the heating period, heating firm must charge a portion of the costs incurred due to heat supply, the cost associated with the measured heat. Outside the lab, no physical quantities such as heat is difficult to measure, heat is made up of multiple parameters. Us to steady state water-heat medium flowing through the radiator to introduce heat metering. Hot water at a steady flow within a small time period $t$ from the inlet piping into the radiator, then mass flow $m$ from the outlet pipe of the water flow back to the heating pipes. This radiator will distribute $\mathrm{w}$ heat to the surrounding air. Hot water energy is determined by the pressure $\mathrm{P}$ and temperature $\mathrm{T}$ the thermodynamic parameters, which said thermodynamics enthalpy $(\mathrm{H}=\mathrm{H}(\mathrm{P}, \mathrm{T}))$.During the heating process, after the heat sink cooling, enthalpy of hot water heating pipes in the imported value down from $\mathrm{H}_{1} \mathrm{H}_{2}$ exit enthalpy value. If using mathematical formulas to express this hot-swappable engineering, assuming constant pressure and constant hot water prerequisite for dynamic and potential energy. In accordance with the laws of thermodynamics, systems into energy and system out of energy equivalent, simplified equation is:

$$
W=m\left(H_{1}-H_{2}\right)=m \cdot \Delta H
$$

That is to say, emitted by the radiator heating power $\mathrm{w}$ is equal to the enthalpy difference times the flow rate $\mathrm{m}$. An entire heating season, total calories $\mathrm{Q}$ through the formula (1) free power $\mathrm{w}_{0}$ to $\mathrm{T}_{1}$ in short score, and that's certain points boundaries, should be predicated on keeping the system stable, this formula (2):

$$
Q=\int_{t_{0}}^{t_{1}} m \cdot \Delta H \cdot d t
$$

Formula (2) $\mathrm{m}$ and time period $\mathrm{t}$ is very simple in the flow measurement differential enthalpy $h$, direct measurement is almost impossible[1]. So people came up with simple approximation method for measuring users actually use heat produced according to these simple methods of measuring the heat meter, we can instrument readings to determine heat loss.

\section{THERMALMEASURING NSTRUMENT}

Winter in cold regions in order to maintain normal production and life, you'll need to fee for supplementary heat to compensate for the heat loss of the building, and when the room temperature remains stable when the buildings heat loss is equal to the indoor heat exchanger the heat emitted thermal heat loss is equal to that part of the pipeline. 
As shown in Figure 1, heat metering principle is by measuring the heat pipes to the housing of the thermal value of $\mathrm{Q}_{1}$ and outflow of heat from the heating pipelines of housing poor value for $Q_{3}$, resulting in users actually use heat value of $\mathrm{Q}_{2}$ :

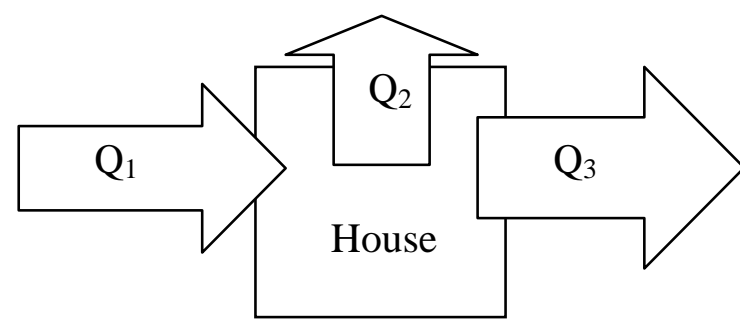

Figure 1

Hot water at a high temperature of the heat source for the user, gives off a certain amount of heat at a low temperature flow in thermal pipe network, this process provides thermal energy for the user. For a certain period, the following equation to calculate the users to get the thermal value:

$$
Q_{2}=\int K \times\left(T_{1}-T_{3}\right) \times d V
$$

where, $\mathrm{Q}_{2}=$ users consume calories; $\mathrm{K}=$ correction coefficient of heat and weight; $\mathrm{T}_{1}=$ water temperature; $\mathrm{T}_{3}=$ water temperature

Measuring heat need two temperature sensors, a flow meter and a digital totalizer, these devices heat metering of heat meter

Two sensors are used to measure supply and return water temperature. Now commonly used a thermistor and Platinum two materials, thermal resistance due to the different resistance values at different temperatures, totalizer according to different resistance values based on the appropriate formula to calculate the corresponding temperature value.

Hot water flow meter is used to measure the user traffic. Usually differential pressure flowmeter, flowmeters ultrasonic flowmeters, Vortex flowmeters, volumetric flowmeter and so on. The flow meters are mainly used to heat meters, mechanical differential pressure flowmeter Electromagnetic Flowmeter.

Totalizer or Integrator is the temperature from temperature sensors and flow meters and flow signal through the calculated temperature and flow rate, calculate heat users consume calories and other parameters. Usually totalizer display data are: cumulative calories, total running time, transient flows, cumulative flow, supply and return water temperature and temperature difference.
3 PRACTICAL APPLICATION OF HOUSEHOLD HEAT METERING OF CENTRAL HEATING IN FOREIGN COUNTRIES

1970's after the oil crises of the last century in promoting central heating household metering process, how to choose specific ways of measuring and metering heating, raise economic issues of common concern. Primarily take the form of central heating metering and charging some European countries, and has formed a relatively complete system of heating. Heating charges are charged based on the actual heat and charging method of the reference area. In terms of heat metering, as countries differ from the proportion of various fuels in energy consumption, building envelope insulation levels varies, the weight difference of central heating, and different political and economic system, have contributed to differences on the household heat metering and charging in progress, with Germany and Denmark is more advanced.

In the early 1970 of the 20th century, Federal Germany Government through an on-demand billing billing methods, make the buildings heating heat and general merchandise as both public and private, the price of commodities can be measured. Due to the huge number of heating energy consumption of buildings, Federal Germany when considering energy-saving, the Administration is very concerned about this aspect. In the first building energy efficiency Act was promulgated in July 1976, and subsequently launched in August 1977 the building insulation code, and then over a period of more than 20 years on four occasions amended the law, now the latest revision in 2006. The regulations of building heat consumption indicators from the initial general building falling $700 \mathrm{kwh} / \mathrm{m} 2$ a to 1982 , last reached the second revised edition of the 300 $\mathrm{kWh} / \mathrm{m} 2 \mathrm{a} 200640 \mathrm{kWh} / \mathrm{m} 2 \mathrm{a}$ of the latest civil buildings energy consumption, dropped a total of $1750 \%$.Germany due to high latitude regions, and lack of domestic energy reserves, winter is long, so the history of spontaneous metering and charging the State-owned market. In 1981, the then Federal Germany has enacted mandatory hot water and heat metering and charging regulations, under the ordinance, before June 1984 all new construction and renovation of metering devices must be installed in high-rise buildings and charging. After the reunification of the two Germany, Germany by law the original democratic Germany has until December 31, 1995, implementing heat metering and charging. Germany after the introduction of heat metering reform policy can save 2 million ton of fuel oil per year, with each level decreasing average fuel consumption of the Federal States. Heat metering reform not only inspire people to conserve heat, and to encourage building of thermal 
engineering perspective to judge the quality of residential.

Denmark is located in Northern Europe, heating period from September to May of the following year, nearly 9 months. Denmark domestic heating charge method charge by the area in the 60 's, the 70 's and, instead of charging hot water flow rate, to 80 , according to Denmark by law, instead of charging heating heat. Heating companies with real operating costs while avoiding problems with financial institutions when calculating the costs. Under normal circumstances, Denmark heat in the heating sector consists of two parts: the fixed fees and variable costs. Fixed-fee includes: sticker fees, online service fees and other fixed costs for network access. Network access charge is a capital cost of heating systems, including heat transfer in thermal pipe network construction, the construction cost of public facilities such as stations and heat source.Net charge is determined by the users to the heating units according to their actual level of heating area and building heat consumption required to pay. Online service fee is due during the heating operation, in order to ensure normal production and distribution of heat energy, for heating equipment, pipeline network to carry out the necessary maintenance and repair costs.

\section{APPLICATION OF HEATING METERING IN URBAN CHINA}

From 2003 until the end of 2009, there have been more than 40 cities in North China to participate in heat metering reform and realization of heat metering and heating 198 million square metres, by charging area of 6400 square meters. Ministry of housing and urban-rural development in 2008 identified 12 heating metering reform cities, which together complete the heat metering and charging more than 28 million square meters. Complete heat metering and charging 15 million square meters in Beijing, heat metering and charging completed 8 million square meters in Tianjin, Tangshan finish 2.38 million square meters, the Chengde finished 1.26 million square meters. Statistics show that after implementing heat metering and charging, both the heating enterprises and the user has a large degree of energy saving and consumption reduction.

Beijing development and Reform Commission and Beijing Municipal Administration on households in parts of the building, in 2006, the Commission issued notifications on the pilot implementing heat metering and pricing requested: "one or two system hot prices. Heat price basic heat and measure heat two-part. Among them, the fundamental standards of heat price 12 Yuan/building square meters area, imposed by the heating season according to the actual area;
Measuring section by 0.16 Yuan/kWh, imposed by user heat meters heat. "Gorgeous garden community, North of Beijing Lu Fong home community, Sun garden, Sing Tao garden community, five residential buildings, leading apartment community for household metering pilot, have gained valuable experience and a large energy saving effect.

Tianjin introduced in 2000 on the transformation of residential central heating rate mechanism notice, requested, in areas where conditions are ripe to implement charging, encourages users to expenditure on energy conservation and reduce heat.2006 Tianjin based on heat price, based on developed two system hot prices.

Tianjin meijiang Jade Garden the Moonlight garden, water garden, Crescent community, Lai CAI Li carried out pilot work on heat metering and charging of residential quarters, and achieved good results.

\section{SIGNIFICANCE OF HOUSEHOLD METERING OF CENTRAL HEATING IN CHINA}

First of all, heat system has mobilized Governments, the enthusiasm of residents, housing development companies and heating businesses, and gradually form a heating mechanism of investment diversification, satisfaction rates were jacked up the heating area and heating. Tianjin City heating system reform imposed in 2000 and 2001 two years after additional heating an area of 21 million square meters, heat the fastest for two years.

Secondly, user contribution consciousness raising, increasing rates and fees, heating increased the efficiency of enterprises. As has the law on his side, and clarify payment principal, residents pay initiative clearly has improved. According to statistics, after the heat supply system, heating rate up to $90 \%$ or more, heating supply companies have been guaranteed their benefits.

Again, the heat enterprises establishing market economy ideas primary, grades have improved significantly in quality and services for heating. Heat supply system in heat supplying enterprises toward the market, users become God, this makes heating enterprises and consciously shift attitudes and take the initiative to improve the quality of service.

In short, experience of pilot areas for our large range of thermal system provides valuable experience in promotion, for the nationwide introduction of heat metering of heating industry reform has laid a good foundation.

\section{REFERENCES}

[1] Joachim Wien, Handbuchder Heizkostenabrechnung, Auflage, Wemer Verlag, 2005, 177-178. 